\title{
Development and validation of a structured observation scale to measure responsiveness of physicians in rural Bangladesh
}

Taufique Joarder $^{1 *}$ (D), llias Mahmud ${ }^{1,2}$, Malabika Sarker ${ }^{1}$, Asha George ${ }^{3}$ and Krishna Dipankar Rao ${ }^{4}$

\begin{abstract}
Background: Responsiveness of physicians is the social actions that physicians do to meet the legitimate expectations of service seekers. Since there is no such scale, this study aimed at developing one for measuring responsiveness of physicians in rural Bangladesh, by structured observation method.

Methods: Data were collected from Khulna division of Bangladesh, through structured observation of 393 patientconsultations with physicians. The structured observation tool consisted of 64 items, with four Likert type response categories, each anchored with a defined scenario. Inter-rater reliability was assessed by same three raters observing 30 consultations. Data were analyzed by exploratory factor analysis (EFA), followed by assessment of internal consistency by ordinal alpha coefficient, inter-rater reliability by intra-class correlation coefficient (ICC), concurrent validity by correlating responsiveness score with waiting time, and known group validity by comparing public and private sector physicians.

Results: After removing items with more than 50\% missing values, 45 items were considered for EFA. Parallel analysis suggested a 5 -factor model. Nine items were removed from the list owing to $<0.50$ communality, $<0.32$ loading in unrotated matrix, and $<0.30$ on any factor in rotated matrix. Since 34 items (i.e., the number of remaining items after removing nine items by EFA) were loaded neatly under five factors, explained $61.38 \%$ of common variance, and demonstrated high internal consistency with coefficient of 0.91, this was adopted as the Responsiveness of Physicians Scale (ROP-Scale). The five factors were named as 1) Friendliness, 2) Respecting, 3) Informing and guiding, 4) Gaining trust, and 5) Financial sensitivity. Inter-rater reliability was high, with an ICC of 0.64 for individual rater's reliability and 0.84 for average reliability scores. Positive correlation with waiting time (0.51), and higher score of private sector by 0.18 point denote concurrent, and known group validity, respectively.
\end{abstract}

Conclusions: The ROP-Scale consists of 34 items grouped under five factors. One can apply this with confidence in comparable settings, as this scale demonstrated high internal consistency and inter-rater reliability. More research is needed to test this scale in other settings and with other types of providers.

Keywords: Responsiveness, Human resources for health, Physicians, Psychometrics, Health systems, Bangladesh

\footnotetext{
* Correspondence: joardernddc@yahoo.com

'BRAC James P Grant School of Public Health, BRAC University, 68 Shahid

Tajuddin Ahmed Sharani, Level 6, icddr,b Building, Dhaka, Mohakhali 1212,

Bangladesh

Full list of author information is available at the end of the article
} International License (http://creativecommons.org/licenses/by/4.0/), which permits unrestricted use, distribution, and reproduction in any medium, provided you give appropriate credit to the original author(s) and the source, provide a link to the Creative Commons license, and indicate if changes were made. The Creative Commons Public Domain Dedication waiver (http://creativecommons.org/publicdomain/zero/1.0/) applies to the data made available in this article, unless otherwise stated. 


\section{Background}

Responsiveness of health care providers is an essential attribute of their performance. The concept of responsiveness has appeared in the literature on human resources for health $(\mathrm{HRH})$. In 2004, the Joint Learning Initiative on $\mathrm{HRH}$ used the term 'responsiveness' in the context of $\mathrm{HRH}$, but did not elaborate further [1]. In 2006, Dieleman and Harnmeijer [2] proposed an analytical framework for HRH performance measurement. This framework suggested four domains of $\mathrm{HRH}$ performance, including responsiveness. The World Health Report of 2006 also used the same framework around the same time [3]. However, none of these reports provided any clear definition of $\mathrm{HRH}$ responsiveness. Based on literature on responsiveness, patient satisfaction, service quality, doctor-patient communication, as well as relevant studies in other fields (e.g., gender sensitivity, cultural competency) [4], in this paper, we adopted the following definition of $\mathrm{HRH}$ responsiveness: "social actions by health providers to meet the legitimate expectations of service seekers".

By the term 'social action', actions of health providers related to the therapy or technical aspects of care are excluded; only the non-medical aspects of care are included under $\mathrm{HRH}$ responsiveness. The term 'legitimate expectation' used in this definition demands explanation. Thompson and Sunol [5] classified expectations as: 1) ideal expectations- clients' idealistic perception about available services; 2) predicted expectations- clients' realistic expectations based on experiences, information about available services, etc.; 3) normative expectationsclients' expectations about what ought to happen; and 4) unformed expectations- clients' unarticulated expectations (due to various reasons such as lack of understanding, difficulty expressing in language, fear, anxiety, social norms, etc.). De Silva [6] argued, 'legitimate expectation' is aligned with the concept of 'normative expectations'. She defined 'legitimate' as, '...conforming to recognized principles or accepted rules and standards' (p. 04), and suggested legitimate expectations be determined based on ethical norms and values.

Responsiveness of HRH, such as physicians, is important as lack of it may dissuade patients from early care seeking, diminish their interest in adopting preventive health information [6-8], and decrease their trust in health service providers [9]. Studies also indicate a discourteous attitude in physicians often compromises care-seeking by specific population groups such as the elderly, patients suffering from non-communicable diseases [10], expectant and new mothers [11], and the lesbian-gay-bisexual-transgender (LGBT) community [12-14], leading to compromised wellbeing.

Responsiveness is also important in Bangladesh health systems context. According to three surveys from 1999,
2000 , and 2003, the most important predictor of satisfaction of patients with health providers was found to be the behavior of the providers with the patients [15-17]. Dissatisfaction among service seekers over the provider's behavior has often been expressed in the form of physical violence, as reported by many recent media reports [18-20], as well as by scientific studies [21-23]. Physicians also responded to these acts by holding strikes and refusing services [24-26]. These incidents indicate how important responsiveness of physicians is in the health systems context of countries like Bangladesh.

There are very few studies on the responsiveness of HRH [27-30], especially on physician responsiveness. Among these studies, one primarily focused on $\mathrm{HRH}$ performance and responsiveness was discussed as a component of performance, but the psychometric methods of developing the measurement tool was not described [28]. Another study involved telephone interviews in eight European countries, the context of which is much different than Bangladesh [27]. Another study from Brazil described the psychometric steps in developing an instrument to assess the responsiveness of nurses [30]. Another study was from Thailand; and it employed simulated patient method to analyze degree of responsiveness of physicians; but did neither clarify the concept of responsiveness nor investigate the reliability and validity of the tool used [29].

Since responsiveness is shown by service providers and is experienced by service seekers, the data need to come from the actual interaction of both parties. Therefore, in the context of this study, where recording the actual behavior of the physicians is intended, observing the actual interaction, instead of interviewing the clients or providers, can achieve this goal better. In similar studies, different approaches-such as reviewing patients' records, direct observation of provider, interviews of providers, exit interviews with patients, and simulated patients methods-have been attempted and compared [31-33]. Franko, Daly, Chilongozi, and Dallabetta [32] showed direct observation to be the method of choice (comparing direct observation with provider interviews and simulated patients-in the context of quality of case management of sexually transmitted diseases); however, several studies discussed caveats of this method. For example, service providers may change their behavior when they are aware that they are being observed (Hawthorne effect) [34-36]. But Leonard and Masatu [34] showed in their study that the performance of the observed physicians tend to return to the preobservation state after the tenth observation. Based on these findings from other studies, we adopted the 'structured observation' (SO) method [37], and allowed the first 10 observations to serve as 'washout' consultations. We recorded only the eleventh 
observation in order to avoid or at least minimize the potential Hawthorne effect.

The aim of this study was to develop a scale for measuring responsiveness of physicians in rural Bangladesh. The literature review highlighted the lack of a psychometrically validated scale to measure physician responsiveness in low and middle-income country contexts. By developing such a scale in the context of rural Bangladesh, this paper will add to our understanding of responsiveness and its measurement. Further, it provides a tool which researchers in Bangladesh and other contexts can use to measure health worker responsiveness.

\section{Methods}

A cross-sectional survey of physicians was conducted in Khulna, Bangladesh between December 2014 and January 2015, using an SO checklist.

\section{Sampling}

In this study, we observed consultation sessions of formal sector physicians working either in the public or private sectors. They usually hold a minimum of an MBBS degree (or equivalent foreign degree), and are licensed formally through Bangladesh Medical and Dental Council. The observations were done only in outpatient settings (i.e., consultation rooms) and with the general practitioners. Cases requiring emergency or inpatient care (e.g., assaults, road traffic accidents, poisoning, etc.); or cases requiring additional privacy and confidentiality (e.g., sexually transmitted infections, gynecological conditions, etc.) or physicians' consultations with children under 18 years were excluded.
A common approach for calculating sample size for factor analysis is five to 10 respondents per item [38-40]. The ratio we adopted was 6:1. Since the initial SO tool consisted of 64 items, we needed a total of 384 physician-consultation observations. However, we sampled 400 physicians to observe their consultations, anticipating unavailability of some physicians during the data collection period (December 2014 and January 2015).

\section{Recruitment procedure}

A list of all physicians who were likely to be present during the data collection period was prepared beforehand. Since most of the physicians were concentrated in and around the Khulna district under Khulna division, we centered in Khulna district and then expanded our field around Khulna district until we reached the desired number (Fig. 1). We chose the census method, as there were no sufficient physicians for sampling. We managed to collect data from 393 consultation sessions (one session per physician) - 195 from public sector and 198 from private sector. The physicians were initially contacted by the first author; then again by the Research Assistant (RA) prior to the observation, i.e., during consent seeking. All but two physicians consented the data collection. The unit of data generation was the observation of consultations; not the individual physicians or the patients per se. Thus, a physician was counted in the public sector if $\mathrm{s} / \mathrm{he}$ was observed in a public sector setting (e.g., Upazila Health Complex); and private sector if observed in a private sector setting (e.g., clinic, pharmacy, chamber in residence, etc.).

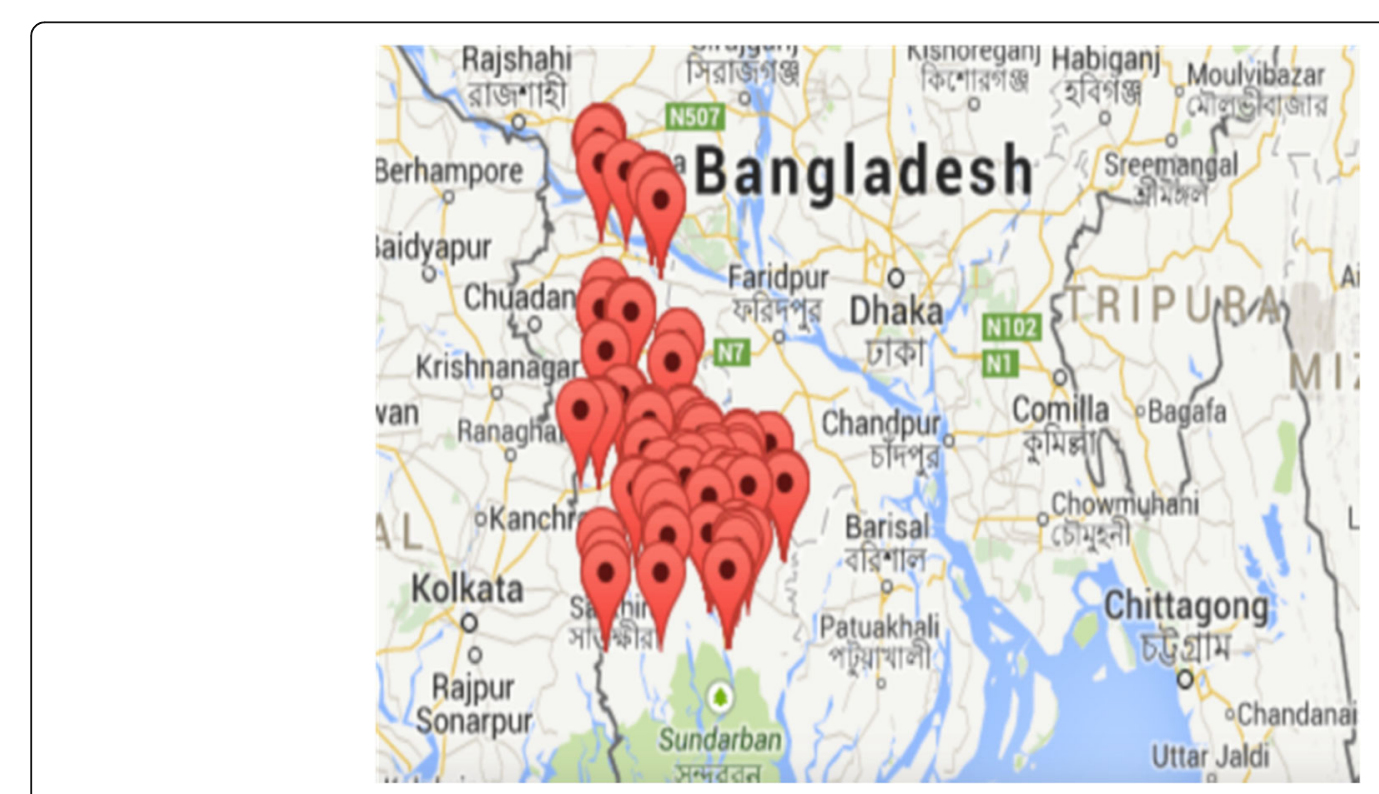

Fig. 1 Map of sampled consultations 


\section{Measurement model and item generation}

The first step of scale development is to determine the unobservable latent variable and the observable indicators or items that would measure the intended latent variable [38]. In this model, the latent variable is responsiveness, which would be measured through 64 observable items or indicators. These items were generated through formative qualitative research, and review of relevant literature [4] (for source of each item, please refer to Additional file 1).

Based on the initial item-pool, an SO tool was developed, with observable response categories (the tool is available as Additional file 2). Each response category was anchored with a scenario. In the SO tool with Likert type responses, response category ' 1 ' was the lowest score, which represented a physician lacking responsiveness at all. Scenario for response categories ' 2 ' was representative of a typical physician while scenario for ' 3 ' was of a better than average responsive physician. Response category ' 4 ' was the best practice or a textbook scenario. Items that could not be observed due to inapplicability in the given context or any other reasons were coded as 'not applicable'. The scenarios for response categories were developed through a qualitative study [4], but category ' 4 ' scenarios were mostly taken from text books on clinical practice. The opposite to those were scenario ' 1 's. The middle ones (i.e., '2' and ' 3 ') were directly derived from the qualitative data, where patient respondents commented on what they expected from a responsive physician. These scenarios were further calibrated later through inputs from a series of field tests, involving 20 RAs. Their field-based experiential inputs were integrated through group discussions over a period of 10 days. An even number of responses was adopted to avoid choosing the neutral option by raters, which is typically the middle option in an odd-number response pool [38].

\section{Data collection}

The cloud-based mobile software Magpi [41] was used for data collection. The RAs were instructed not to take out the SO tool in front of the physicians. They took notes during the observation and then came out of the room and recorded in their notebook the findings, guided by the hard copy of the SO tool. Then they inputted the data in their phones, uploaded the data, and sent a confirmatory message to the first author.

The RAs recorded the observation of only the 11th patient (allowed the first 10 patients as 'washout' observations, in order to minimize Hawthorne effect by the observed physicians), came out of the consultation room with the patient and asked the patient some background information (age, gender, and education). RAs were recommended to observe two consultations per day; but they were strictly instructed not to observe more than three in a day, as large number of observations in a day might diminish data quality.

For the inter-rater reliability test, the first author-along with two RAs-collected the data. The data collection procedure was the same as before, but three observers did the observation simultaneously, but uploaded the data separately. Thirty consultations-15 in the public sector and 15 in the private sector- were observed.

\section{Statistical analysis}

Data collected through Magpi software were imported into Stata version 12.1 for data management, cleaning, missing value imputation, and descriptive analyses [42]. Items with more than $50 \%$ non-response or missing values were dropped (shown in Additional file 1, in italicized font), and the remaining missing values in the dataset were imputed by 'hotdeck' method [43]. Univariate and multivariate analyses of remaining items were preformed to examine skewness and kurtosis, in order to check the suitability for using polychoric correlations. Skewness or kurtosis of any item greater than one in absolute value in univariate analysis; or a statistically significant skewness or kurtosis in multivariate test support the use of polychoric correlation matrix [44].

Exploratory factor analysis (EFA) was conducted using an open-source software, FACTOR version 9.3.1 [45]. Polychoric correlation matrix was used for the purpose, which is suitable for scales with ordinal response categories [46-48]. The software FACTOR performs the check of suitability of data for factor analysis by Bartlett's test and Kaiser-Meyer-Olkin (KMO) test. A statistically significant Bartlett's test and $>0.80 \mathrm{KMO}$ statistic indicate the data-suitability for EFA [44]. We chose the minimum rank factor analysis (MRFA) as extraction method [49-51], and for deciding the number of factors to be extracted, adopted the variant of parallel analysis based on MRFA, which is suitable for categorical variables [49]. Factors were rotated using Promin oblique rotation method [46].

After EFA, the model was checked for internal consistency, using the ordinal alpha coefficient, based on polychoric correlation matrix [50], using statistical software $\mathrm{R}$, version 3.1.3 [51]. The corrected item-total correlation was also calculated with a hope to achieve a correlation over 0.35 [39].

For optimizing scale length by dropping items, following three criteria were used: 1) items with communality $<0.50$; 2) loading of $<0.32$ of an item on any of the unrotated factors; and 3) loading of $<0.30$ (a default value set by the software FACTOR) of an item on any of the rotated factors. Several factor solutions were examined and the 5-factor solution was retained because adding 
or removing an extra factor could not improve the model in any way (increasing the communality of the items, and/or increasing the loading of items). After three iterations, nine items were dropped and the 34item model was considered final.

Finally, the ordinal alpha coefficient was assessed to see if dropping an item would increase the alpha coefficient and increase the internal consistency of the model. Since no such item was found, we finalized the 34-item scale, grouped under five factors or subscales. We ran the whole EFA again and found the model optimum and adequate (no item with low communality, each item sufficiently loaded on one factor, high alpha coefficient).

The responsiveness scale score was measured as the mean of the 34 items' scores. Since this is a continuous value, inter-rater reliability was measured using intraclass correlation coefficient (ICC) [52]. We employed three same raters to rate all the consultations (30 consultations each), and ICC $(2,1)$ and $(2,3)$ was calculated. A value of ICC less than 0.40 is considered poor, between 0.40 and 0.59 is fair, between 0.60 and 0.74 is good, and between 0.75 and 1.00 is excellent [53]. We hoped to achieve a correlation value of 0.60 or higher (i.e., good inter-rater reliability).

Criterion validity of the newly developed Responsiveness of Physicians Scale (ROP-Scale) was assessed examining concurrent validity of the scale and known group validation. To investigate concurrent validity, Pearson correlation test was used; and two-sample $t$-test was used for known group validation. For investigating concurrent validity, correlation between ROP-Scale score and consultation time was assessed under the assumption that, responsiveness would be positively correlated with consultation time. Although there is no study establishing this relationship directly, there are studies showing that patients expect more time from physicians on consultation, and that consultation time is a predictor of satisfaction [54]. A correlation coefficient of 0.40 or higher was considered acceptable. For known group validation, the mean responsiveness score of the observations in public sector was compared to that of private sector, under the assumption that physicians in private sector would have statistically significantly higher mean responsiveness score than that in the public [55-57].

\section{Results}

\section{Background characteristics}

\section{Items retained for factor analysis}

The initial SO tool consisted of 64 items, 19 of which had more than $50 \%$ missing values; hence were dropped from any subsequent analyses (Additional file 1). Univariate analysis of the interim scale with 45 variables (i.e., after dropping 19 items) revealed that 21 out of 45 items had skewness or kurtosis greater than one in absolute value. The multivariate test for skewness was not statistically significant, but that for kurtosis was significant with $p$-value $<0.01$. These suggest using polychoric correlation instead of Pearson's correlation for factor analysis. Bartlett's test was statistically significant (with statistic of 6096.1; df of 990 and $p$-value <0.01), and KMO statistic 0.83 ; both of which indicate the data to be suitable for factor analysis.

\section{Characteristics of sample}

Table 1 summarizes the characteristics of the consultations, physicians, and patients. Half of the observations were done in the public sector and half in the private sector. Average consultation time was five minutes. The majority of the physicians were below 40 years of age and most of them were male. More than half of them had less than two years of experience of working in rural areas. Almost one third of them belonged to the same sub-district where they were observed. Patients were from different age groups, but most of them were females (60\%). Almost half of them had less than or equal to primary education, about one third had up to secondary education and the remaining had more than that.

\section{Factor analysis \\ Determining the number of factors to retain}

Parallel analysis suggested the extraction of a 5-factor model. There were five factors whose real data percentage of common variance exceeded the mean or 95 percentile of that of the random datasets generated by the parallel analysis method.

\section{Factor extraction and rotation}

Based on the factor extraction criteria mentioned in the methods section, the following eleven items were dropped from the model: Self identification by doctor, taking consent in general, involving patients in carerelated decision making, considering religious and cultural orientation of the patient, legibility of prescription, not showing hierarchical difference, gender sensitivity, interruption during consultation, appearance of doctor, allowing patient to ask questions, and relaxedness and confidence. In the final factor analysis with 34 items and five factors, no item was found to be eligible for being dropped, based on the three criteria mentioned earlier. The remaining items neatly loaded (none of the remaining items had $<0.50$ communality, $<0.32$ loading in un-rotated matrix, and $<0.30$ on any factor in rotated matrix) on five factors, as shown in Table 2.

The items 'Greetings by doctor' and 'Closing salutation by doctor' were also loaded somewhat heavily (with loadings of 0.34 and 0.33 respectively) on 'Friendliness' factor. But, since their loading was slightly higher in the 'Respecting' domain, they are placed under that domain. 
Table 1 Characteristics of the consultations, physicians, and patients

\begin{tabular}{|c|c|c|}
\hline \multicolumn{2}{|l|}{ Variable } & \multirow{2}{*}{$\begin{array}{l}\text { Value } \\
195(n)\end{array}$} \\
\hline Observation setting & Public sector & \\
\hline & Private sector & $198(n)$ \\
\hline \multicolumn{2}{|c|}{$\begin{array}{l}\text { Self-reported number of patients seen by physicians } \\
\text { in that setting (public or private) per day (Mean and } \\
\text { Standard Deviation) }\end{array}$} & $\begin{array}{l}30.35 \\
(17.81)\end{array}$ \\
\hline \multicolumn{2}{|c|}{ Consultation time in minutes (mean and standard deviation) } & $\begin{array}{l}5.04 \\
(2.45)\end{array}$ \\
\hline \multirow[t]{2}{*}{ Gender of physician } & Male & $78.37(\%)$ \\
\hline & Female & $21.63(\%)$ \\
\hline \multirow[t]{4}{*}{ Age of physician } & Less than 30 Years & $33.84(\%)$ \\
\hline & 30 to less than 40 Years & $35.62(\%)$ \\
\hline & 40 to less than 50 Years & $11.45(\%)$ \\
\hline & $\begin{array}{l}\text { More than or equal to } \\
50 \text { years }\end{array}$ & $19.08(\%)$ \\
\hline \multirow{2}{*}{$\begin{array}{l}\text { Origin of physician (i.e., whether } \\
\text { from the same upazila) }\end{array}$} & Local & $33.33(\%)$ \\
\hline & Not local & $66.67(\%)$ \\
\hline \multirow[t]{4}{*}{ Year of graduation of physician } & After 2000 & $68.18(\%)$ \\
\hline & Between 1990 and 2000 & $11.70(\%)$ \\
\hline & Between 1980 and 1990 & $17.30(\%)$ \\
\hline & Before 1980 & $3.82(\%)$ \\
\hline \multirow{4}{*}{$\begin{array}{l}\text { Rural work experience of } \\
\text { physician }\end{array}$} & 2 Years or less & $51.91(\%)$ \\
\hline & More than 2 to 5 years & $16.03(\%)$ \\
\hline & More than 5 to 10 years & $9.92(\%)$ \\
\hline & More than 10 years & $22.14(\%)$ \\
\hline \multirow{3}{*}{$\begin{array}{l}\text { Type of medical college the } \\
\text { physician passed from }\end{array}$} & Public & $92.62(\%)$ \\
\hline & Private & $6.62(\%)$ \\
\hline & Foreign & $0.76(\%)$ \\
\hline \multirow[t]{2}{*}{ Gender of patient } & Male & $39.69(\%)$ \\
\hline & Female & $60.31(\%)$ \\
\hline \multirow[t]{4}{*}{ Age of patient } & Less than 30 years & $23.16(\%)$ \\
\hline & 30 to less than 40 years & $20.87(\%)$ \\
\hline & 40 to less than 50 years & $24.94(\%)$ \\
\hline & $\begin{array}{l}\text { More than or equal to } \\
50 \text { years }\end{array}$ & $31.04(\%)$ \\
\hline \multirow[t]{4}{*}{ Level of education of patient } & Illiterate & $21.88(\%)$ \\
\hline & $\begin{array}{l}\text { Up to primary (5 Years) } \\
\text { education }\end{array}$ & $26.72(\%)$ \\
\hline & $\begin{array}{l}\text { Up to secondary (10 Years) } \\
\text { education }\end{array}$ & $32.06(\%)$ \\
\hline & $\begin{array}{l}\text { More than secondary } \\
\text { education }\end{array}$ & $19.34(\%)$ \\
\hline
\end{tabular}

In this model, the KMO statistic improved further to be 0.84 , and it explained $61.38 \%$ of common variance. The highest two inter-factor correlations were between factors three and four (Respecting and Informing and guiding) and factors one and three (Friendliness and
Respecting) (Table 3). These correlations justify the use of an oblique factor rotation method instead of an orthogonal method. These high correlations also indicate that some items under the domain 'Respecting' can also be seen as a gesture of friendliness and aptitude of the physician in informing and guiding the patient.

Since the scale is intended to measure the responsiveness of physicians, it has been named as the Responsiveness of Physicians Scale, or in short ROP-Scale. The scale is composed of five sub-scales: 1) Friendliness (with items such as asking patient's name, engaging in social talks, etc.), 2) Gaining trust (with items such as earning trust of patients, not being involved in illegal activities, etc.), 3) Respecting (with items such as showing respect explicitly, listening to patient's complaints completely, etc.), 4) Informing and guiding (with items such as explaining the cause of disease to the patient, explaining the diagnosis of disease to the patient, etc.), and 5) Financial sensitivity (with items such as considering socio-economic status of the patient, informing the cost of treatment, etc.). The final ROP-Scale, along with the definition of the sub-scales and associated items, has been shown in Table 4 .

To measure the aggregated ROP-Scale score, the mean of the 34 items was calculated. Subscale scores were calculated in the same way. The mean responsiveness score and subscale scores of the whole sample as well as the sample disaggregated by their sectoral affiliation (i.e., public and private sector) has been shown in Table 5 .

\section{Scale reliability and validity Reliability}

The internal consistency of the whole scale was high with an alpha value of 0.91 . The alpha value for subscales Friendliness, Gaining trust, Respecting, Informing and guiding, and Financial sensitivity were $0.86,0.77$, $0.87,0.86$, and 0.84 , respectively.

Corrected item-total correlations of most of the items were also high in the overall responsiveness scale, ranging from 0.21 to 0.65 , with the exception of two items-Not using jargon and Not being involved in illegal activities. However, in respective subscales, these items had high corrected item-total correlations (0.41 and 0.48 respectively).

In order to measure inter-rater reliability, ICC was counted. ICC $(2,1)$ or individual rater's reliability score was 0.64 (95\% confidence interval $0.37,0.81$ ), while ICC $(2,3)$ or average reliability score for three raters was 0.84 ( $95 \%$ confidence interval $0.64,0.93$ ).

\section{Validity}

We found a positive correlation of 0.51 between responsiveness score and consultation time, which indicates acceptable concurrent validity of the ROP-Scale. The two 
Table 2 Rotated pattern matrix (34 items)

\begin{tabular}{|c|c|c|c|c|c|}
\hline Variable & Friendliness & Gaining trust & Respecting & Informing and guiding & Financial sensitivity \\
\hline Greetings by doctor & 0.34 & & 0.49 & & \\
\hline Asking patient's name & 0.42 & & & & \\
\hline Engaging in social talks & 0.86 & & & & \\
\hline Asking about patient's family & 0.85 & & & & \\
\hline Friendliness & 0.88 & & & & \\
\hline Showing respect explicitly & & & 0.69 & & \\
\hline Listening to patient's complaints completely & & & 0.84 & & \\
\hline Listening to patient's complaints attentively & & & 0.77 & & \\
\hline Examining the patient with care & & & 0.47 & & \\
\hline $\begin{array}{l}\text { Suggestions on disease prevention and health } \\
\text { promotion in general }\end{array}$ & & & & 0.58 & \\
\hline Giving courage and reassurance & 0.54 & & & & \\
\hline Earning trust of patients & & 0.82 & & & \\
\hline Service oriented, not businesslike behavior & & 0.87 & & & \\
\hline Considering socio-economic status of the patient & & & & & 0.91 \\
\hline Trying to understand socio-economic status of the patient & & & & & 0.82 \\
\hline Informing the cost of treatment/financial counseling & & & & 0.31 & 0.71 \\
\hline Providing financial assistance if needed & & & & & 0.80 \\
\hline Facilitating follow-up & & & & 0.35 & \\
\hline Quantity of issues explained and the quality of explanation & & & & 0.85 & \\
\hline Quantity of issues explained & & & & 0.84 & \\
\hline Asking patient if $s /$ he understood the explanation & & & & 0.37 & \\
\hline Explaining the cause of disease to the patient & & & & 0.81 & \\
\hline Explaining the diagnosis of disease to the patient & & & & 0.73 & \\
\hline Explaining the prognosis of disease to the patient & & & & 0.69 & \\
\hline Explaining the treatment to the patient & & & & 0.45 & \\
\hline Explaining the preventive aspects to the patient & & & & 0.62 & \\
\hline Encouraging patient to ask questions & & & 0.73 & & \\
\hline Listening attentively to patient's questions & & & 0.56 & & \\
\hline Not using jargon & & 0.54 & & & \\
\hline Closing salutation by doctor & 0.33 & & 0.49 & & \\
\hline Non-verbal communication by doctor & & & 0.68 & & \\
\hline Compassionately touching the patient by doctor & & -0.36 & 0.55 & & \\
\hline Not being involved in illegal activities & & 0.70 & & & \\
\hline Sense of humor & 0.76 & & & & \\
\hline
\end{tabular}

Note: Items that are finally retained in the scale under the factors are shown in bold font

Table 3 Inter-factor correlation matrix (34 items)

\begin{tabular}{llllll}
\hline Factor & Friendliness & Gaining trust & Respecting & Informing and guiding & Financial sensitivity \\
\hline Friendliness & 1.00 & & & & \\
Gaining trust & -0.09 & 1.00 & 0.24 & 1.00 & 1.00 \\
Respecting & 0.42 & -0.04 & 0.43 & 0.25 & 1.00 \\
Informing and guiding & 0.40 & 0.11 & 0.22 & \\
Financial sensitivity & 0.25 & &
\end{tabular}


Table 4 The Responsiveness of Physicians Scale (ROP-Scale)

\begin{tabular}{|c|c|c|}
\hline Name of Factor & Definition & Items in domain \\
\hline Friendliness & How a physician communicates with a patient & $\begin{array}{l}\text { 1. Asking patient's name } \\
\text { 2. Engaging in social talks } \\
\text { 3. Asking about patient's family } \\
\text { 4. Friendliness } \\
\text { 5. Giving courage and reassurance } \\
\text { 6. Sense of humor }\end{array}$ \\
\hline Respecting & $\begin{array}{l}\text { How a physician explicitly shows respect to } \\
\text { a patient }\end{array}$ & $\begin{array}{l}\text { 7. Greetings by doctor } \\
\text { 8. Showing respect explicitly } \\
\text { 9. Listening to patient's complaints completely } \\
\text { 10. Listening to patient's complaints attentively } \\
\text { 11. Examining the patient with care } \\
\text { 12. Encouraging patient to ask questions } \\
\text { 13. Listening attentively to patient's questions } \\
\text { 14. Closing salutation by doctor } \\
\text { 15. Non-verbal communication by doctor } \\
\text { 16. Compassionately touching the patient by doctor }\end{array}$ \\
\hline Informing and guiding & How a physician empowers a patient & $\begin{array}{l}\text { 17. Suggestions on disease prevention and health promotion } \\
\text { in general } \\
\text { 18. Facilitating follow-up } \\
\text { 19. Quantity of issues explained and the quality of explanation } \\
\text { 20. Quantity of issues explained } \\
\text { 21. Asking patient if s/he understood the explanation } \\
\text { 22. Explaining the cause of disease to the patient } \\
\text { 23. Explaining the diagnosis of disease to the patient } \\
\text { 24. Explaining the prognosis of disease to the patient } \\
\text { 25. Explaining the treatment to the patient } \\
\text { 26. Explaining the preventive aspects to the patient }\end{array}$ \\
\hline Gaining trust & $\begin{array}{l}\text { How a physician may gain trust of the patients, or } \\
\text { refrains from doing something that may breach } \\
\text { trust of the patients }\end{array}$ & $\begin{array}{l}\text { 27. Earning trust of patients } \\
\text { 28. Service oriented, not businesslike behavior } \\
\text { 29. Not using jargon } \\
\text { 30. Not being involved in illegal activities }\end{array}$ \\
\hline Financial sensitivity & $\begin{array}{l}\text { Understanding financial need of the patients and } \\
\text { providing support if needed, going beyond the } \\
\text { consultation }\end{array}$ & $\begin{array}{l}\text { 31. Considering socio-economic status of the patient } \\
\text { 32. Trying to understand socio-economic status of the patient } \\
\text { 33. Informing the cost of treatment } \\
\text { 34. Providing financial assistance if needed }\end{array}$ \\
\hline
\end{tabular}

sample $t$-tests for the difference in mean responsiveness score revealed that the private sector physicians had significantly higher responsiveness of 0.18 points ( $p$-value $<0.01$ ) (Table 5)-denoting the known-group validity of ROP-Scale.

\section{Discussion and conclusions}

Our study contributed to the development of the ROPScale, with 34 items, grouped under five subscales: Friendliness, Respecting, Informing and guiding, Gaining trust, and Financial sensitivity. These domains and most of the items under each domain are consistent with the relevant studies in this regard (Complete list of items that are aligned with different articles, is available in Appendix 12 of Joarder, 2015 [4]). The scale was found to be reliable, valid, and internally consistent. Another important feature of this study was the use of the same three raters to evaluate inter-rater reliability. This method of calculating ICC is considered useful, as in this method systematic bias between raters is controlled [58].

We found that some items of 'Friendliness' domain (e.g., 'Greetings by doctor' and 'Closing salutation by doctor') were also loaded in the 'Respecting' domain. An explanation of this may be, exchanging greeting words or closing salutation are generally out of therapeutic culture of Bangladeshi physicians [59]. Therefore, if a physician does these, the patients see it as a display of respect rather than a display of just friendliness.

In 'Respecting' domain, items like 'Non-verbal communication by doctor' and 'Compassionately touching the patient by doctor' could arguably be seen as gestures of friendliness. However, in Bangladeshi social context, there is a large power differential, especially in rural areas, between the patients and the physicians [59]. While most of the patients' education falls below the secondary education, the physicians' level of education and social position were very high in comparison. So, there may be a generalized lack of friendliness from physicians [60]. As a result, some friendly gestures like head-nodding or touching the patients were perceived by the patients as a rather respectful demeanor by the physicians.

Most of the items in the 'Informing and guiding' domain are related to providing explanation by the 
Table 5 Responsiveness score of the sample using ROP-Scale

\begin{tabular}{llll}
\hline Scale & Overall mean score $(n=393)$ & Public sector mean score $(n=195)$ & Private sector mean score $(n=198)$ \\
\hline Friendliness & $1.49(0.48)$ & $1.34(0.43)$ & $1.64(0.48)$ \\
Respecting & $2.37(0.41)$ & $2.22(0.39)$ & $2.51(0.38)$ \\
Informing and guiding & $1.80(0.45)$ & $1.68(0.46)$ & $1.91(0.40)$ \\
Gaining trust & $3.38(0.37)$ & $3.45(0.28)$ & $3.32(0.43)$ \\
Financial sensitivity & $1.58(0.59)$ & $1.65(0.64)$ & $1.51(0.53)$ \\
ROP-Scale & $2.07(0.31)$ & $1.98(0.29)$ & $2.16(0.29)$ \\
\hline
\end{tabular}

Note: Standard deviation is shown in the parenthesis

physicians of different aspects related to the disease or condition. Aujoulat, d'Hoore, and Deccache [61] posited that provision of information should be done in a continuous manner, which can be achieved by regular follow-ups. Their suggestions are congruent with this domain, as this domain consists of an item 'Facilitating follow-up' along with the explanation-related items.

Trust, in the context of this research, was conceived as patients' belief that the physicians would act in the best interest of the patients, not in their own interest [9]. Items loaded in the domain 'Gaining trust' are in alignment with this definition, except one item: 'Not using jargon'. An explanation to this item's loading under 'Gaining trust' domain may be using too much technical vocabulary by physicians may depict them in an untrustworthy light. Another feature of this domain is the inclusion of the item 'Not being involved in illegal activities', which is supported by previous studies in Bangladesh $[17,56,59,62-64]$. However, in countries or settings where vigilance or monitoring of the physicians is more scrupulous, or where accountability mechanisms for physicians are better functioning, this item may not seem as appropriate.

The final domain is 'Financial sensitivity', which entails items related to understanding financial status of the patients by doctors and providing support if necessary. A noteworthy feature of this domain is that, most of the items under this domain were derived from the formative qualitative research [4], not from the literature review. The only item that is supported by literature is 'Informing the cost of treatment' $[65,66]$. But interestingly, according to the formative qualitative research [4], physicians in Bangladesh do not consider providing this type of information as their responsibility. Another item 'Providing financial assistance if needed' may be outside of the responsibility of the physicians in settings where pre-payment-based health financing mechanism is established and out-of-pocket payment is uncommon.

It is clear from the above discussion that, while some items of the ROP-Scale are commonly found in other literature, few others are very much context specific, i.e., peculiar to Bangladesh or similar settings. Therefore, caution needs to be maintained in generalizing these items to different settings such as western, or advanced industrialized societies. The scale also needs to be carefully validated for measuring responsiveness of other health workers such as the nurses, community health workers (CHW), etc.

\section{Strengths and limitations of the study}

Despite taking careful measures to ensure psychometric rigor, this research may face some criticisms, which are common for most psychometric scales. Major criticism could fall on the decision rules adopted at different decision points. Using a different decision rule or a different method may bring forth a different model. So, we first tried to ensure face and content validity of the items through repeated consultations with the experts who have reasonable expertise on the subject matter and/or the context of where and among whom the study was conducted [4]. Significant efforts were put in repeated field-tests too.

Criterion (concurrent) validity could not be ascertained properly due to the lack of a gold standard to compare the findings with. Construct validity also could not be assessed. A multi-method approach could be employed for checking construct validity; for example, a separate exit interview tool could have been developed for this purpose. This was not done due to time and resource limitations. Test-retest reliability could not be assessed due to the methodological limitation. As the consultation scenario changes from patient to patient, test-retest reliability was not possible to measure, given the methods adopted for this study (i.e., SO method). However, this could be attempted if an exit interview method was used.

Finally, we acknowledge the fact that separating the 'medical' or 'technical' aspects of care from the 'nonmedical' or 'social' aspects is not straightforward, as many 'social' actions may have implications for 'medical' aspects of care. For example, one of ROP-Scale items, 'Examining the patient with care', despite being included here as a 'social action', has clear 'medical' values. Similarly, many 'medical' actions would render the physician 'responsive' in the eyes of the patients. For example, physicians would touch the patients for various 
therapeutic purposes, which may be considered by patients as a 'social' action' (e.g., Compassionately touching the patient by doctor').

\section{Future research}

The known-group validation in this study, involving investigation of physicians' responsiveness in public and private sector, indicates that there might be difference in the level of responsiveness in these two settings. It may be useful to examine the differences in responsiveness between public and private sector physicians more in-depth. It can also be seen if they differ in terms of all the domains of responsiveness, or they differ only in certain domains.

This study was limited to the physicians working in the outpatients of rural areas of Bangladesh. Future studies can be carried out in various other relevant settings such as in the urban areas, among other professional groups like the nurses, CHWs, etc., in other professional settings like inpatient services, emergency, etc.

This study focused on developing the responsiveness scale, but this did not take into account many potential determinants of responsiveness, which may aid the physicians to be responsive or deter them from being responsive in practice. Understanding of these determinants is crucial to improve the responsiveness and resolve the issues around this topic.

\section{Policy implications}

Since measuring the magnitude of a problem is one of the crucial steps of public health problem solving paradigm [67], this scale can contribute in this regard and assist the policy makers to understand the absolute magnitude (overall responsiveness score), relative magnitude (domain-specific responsiveness score) and distribution (responsiveness score across geographical areas, professional groups, etc.) of the deficiencies in this front.

As performance based payment and other modalities of result based financing mechanism are gaining popularity, public health managers or program implementers would need to measure responsiveness as a part of the performance of HRH. The ROP-Scale can help in evaluating and monitoring $\mathrm{HRH}$ performance; hence it has the potential to be utilized in a performance based payment scheme.

Although our study was done in rural Bangladeshi setting, this may provide conceptual and methodological inputs to conduct similar locally relevant studies in other countries. Series of such studies may aid in developing a tool, robust enough to conduct cross-national comparisons, at least in comparable countries.

\section{Additional files}

Additional file 1: List and sources of all items in quantitative structured observation tool. (DOCX $112 \mathrm{~kb}$ )

Additional file 2: Structured observation tool (full version-64 items). (DOCX 177 kb)

\section{Abbreviations \\ BM\&DC: Bangladesh Medical and Dental Council; CHW: Community Health Worker; EFA: Exploratory Factor Analysis; HRH: Human Resources for Health; ICC: Intra-class Correlation Coefficient; JHSPH: Johns Hopkins School of Public Health; JPGSPH: James P Grant School of Public Health; KMO: Kaiser-Meyer- Olkin; MRFA: Minimum Rank Factor Analysis; RA: Research Assistant; ROP- Scale: Responsiveness of Physicians Scale; SO: Structured Observation}

\section{Acknowledgments}

This manuscript is based on TJ's doctoral dissertation at Department of International Health, Johns Hopkins Bloomberg School of Public Health (JHSPH). The fieldwork was funded and facilitated by the BRAC James P Grant School of Public Health (JPGSPH), BRAC University, Bangladesh. TJ also acknowledges Dr. David Peters from JHSPH, who provided valuable suggestions in data analysis and manuscript development. We are also indebted to the Director General of the Directorate General of Health Services, Government of Bangladesh Dr. Abul Kalam Azad, for approving our data collection from government health facilities. The President of Bangladesh Private Medical Practitioners Association, Dr. Maniruzzaman Bhuiyan, was very kind in extending his support to recruit private sector physicians for this study.

\section{Availability of data and materials}

According to the policy of BRAC James P Grant School of Public Health, BRAC University, all research data and material are stored in the Institutional Data Repository of the mentioned organization. This is freely available to the editor and reviewers on request. Please email to jpgsph@bracu.ac.bd for any queries in this regard.

\section{Consent to participate}

Written informed consent was obtained from both the physician and the patient before starting the observation. However, in order to minimize Hawthorne effect, physicians were not informed which consultation (11th patient) the RA was going to record.

\section{Authors' contributions}

TJ designed the study under the supervision of KR and AG. IM and MS were local supervisors, and they supported in data collection. TJ conducted statistical analysis, under the guidance of KR. All authors contributed to the discussion. TJ produced the first draft and all authors reviewed and approved the final manuscript.

\section{Ethics approval and consent to participate}

Ethical approval was obtained from the Ethical Review Board of BRAC University, Dhaka, Bangladesh. Initial approval was received on 19 August 2014; an amendment to conduct SO of consultations involving real patients was approved on 12 December 2014.

\section{Consent for publication}

Since there are no details on individuals reported within the manuscript, consent for publication of images is not required.

\section{Competing interests}

The authors declare that they have no competing interest.

\section{Publisher's Note}

Springer Nature remains neutral with regard to jurisdictional claims in published maps and institutional affiliations.

\section{Author details}

${ }^{1}$ BRAC James P Grant School of Public Health, BRAC University, 68 Shahid Tajuddin Ahmed Sharani, Level 6, icddr,b Building, Dhaka, Mohakhali 1212. Bangladesh. ${ }^{2}$ Department of Public Health, College of Public Health and 
Health Informatics, Qassim University, Bukayriah, Post box: 828, Post code: 51941 Qassim, Saudi Arabia. ${ }^{3}$ School of Public Health, University of Western Cape, Cape Town, South Africa. ${ }^{4}$ Department of International Health, Johns Hopkins Bloomberg School of Public Health, 615 North Wolfe Street, Suite E8132, Baltimore, MD 20205, USA.

Received: 23 May 2017 Accepted: 10 November 2017

Published online: 21 November 2017

\section{References}

1. Joint Learning Initiative. Human resources for health: overcoming the crisis. California: Global Equity Initiative; 2004 [cited 2014 Mar 26]. Available from: http://books.google.com/books?id=L0Q2AQAAIAAJ\&pgis=1.

2. Dieleman M, Harnmeijer JW. Improving health worker performance : in search of promising practices. Geneva: World Health Organization; 2006.

3. World Health Organization. The world health report 2006: working together for health. Geneva: World Health Organization; 2006.

4. Joarder T. Understanding and measuring responsiveness of human resources for health in rural Bangladesh. Johns Hopkins Bloomberg School of Public Health; 2015.

5. Thompson AGH, Sunol R. Expectations as determinants of patient satisfaction: concepts, theory and evidence. Int J Qual Heal Care. 1995;7: 127-41. [cited 2014 Apr 7]. Available from: http://intqhc.oxfordjournals.org/ content/7/2/127.short

6. De Silva A. A framework for measuring responsiveness. Geneva; 1999. Available from: http://www.who.int/healthinfo/paper32.pdf.

7. Darby C, Valentine N, Murray CJL, De Silva A. World Health Organization: strategy on measuring responsiveness. J Med Philos. Geneva; 2000. Available from: http://www.who.int/healthinfo/paper23.pdf.

8. Njeru MK, Blystad A, Nyamongo IK, Fylkesnes K. A critical assessment of the WHO responsiveness tool: lessons from voluntary HIV testing and counselling services in Kenya. BMC Health Serv Res. 2009;9:243. [cited 2014 Jan 14]. Available from: http://www.pubmedcentral.nih.gov/articlerender. fcgi?artid=2811110\&tool=pmcentrez\&rendertype=abstract.

9. Gilson L. Trust and the development of health care as a social institution. Soc Sci Med. 2003;56:1453-68. Available from: http://www.ncbi.nlm.nih.gov/ pubmed/12614697.

10. Bhojani U, Mishra A, Amruthavalli S, Devadasan N, Kolsteren P, De Henauw $S$, et al. Constraints faced by urban poor in managing diabetes care: patients' perspectives from South India. Glob Health Action. 2013;6:22258. [cited 2014 Mar 26]. Available from: http://www.pubmedcentral.nih.gov/ articlerender.fcgi?artid=3790910\&tool=pmcentrez\&rendertype=abstract.

11. Ekirapa-Kiracho E, Waiswa P, Rahman MH, Makumbi F, Kiwanuka N, Okui O, et al. Increasing access to institutional deliveries using demand and supply side incentives: early results from a quasi-experimental study. BMC Int Health Hum Rights. 2011;11(Suppl 1):S11. [cited 2014 Mar 26]. Available from: http://www.biomedcentral.com/1472-698X/11/S1/S11.

12. Wirtz AL, Kamba D, Jumbe V, Trapence G, Gubin R, Umar E, et al. A qualitative assessment of health seeking practices among and provision practices for men who have sex with men in Malawi. BMC Int Health Hum Rights. 2014;14:20. [cited 2015 Apr 4]. Available from: http://www. biomedcentral.com/1472-698X/14/20.

13. O'Hanlan KA, Cabaj RP, Schatz B, Lock J, Nemrow P. A review of the medical consequences of homophobia with suggestions for resolution. J Gay Lesbian Med Assoc. 1997;1:25-39. [cited 2015 Apr 4]. Available from: http:// link.springer.com/10.1023/B:JOLA.0000007009.83600.ae.

14. Elouard Y, Essén B. Psychological violence experienced by men who have sex with men in Puducherry, India: a qualitative study. J Homosex. 2013;60: 1581-601. [cited 2015 Apr 4]. Available from: http://www.ncbi.n/m.nih.gov/ pubmed/24147588.

15. Aldana JM, Piechulek H, Al-Sabir A. Client satisfaction and quality of health care in rural Bangladesh. Bull World Health Organ. 2001;79:512-7. Available from: http://www.pubmedcentral.nih.gov/articlerender.fcgi?artid= 2566452\&tool=pmcentrez\&rendertype=abstract.

16. Cockcroft A, Milne D, Oelofsen M, Karim E, Andersson N. Health services reform in Bangladesh: hearing the views of health workers and their professional bodies. BMC Health Serv Res. 2011;11(Suppl 2):S8. [cited 2014 Jan 14]. Available from: http://www.pubmedcentral.nih.gov/articlerender. fcgi?artid=3332567\&tool=pmcentrez\&rendertype=abstract.

17. Cockcroft A, Andersson N, Milne D, Hossain MZ, Karim E. What did the public think of health services reform in Bangladesh? Three national community-based surveys 1999-2003. Health res. Policy Syst. 2007;5:1. [cited 2014 Jan 14]. Available from: http://www.pubmedcentral.nih.gov/ articlerender.fcgi?artid=1810295\&tool=pmcentrez\&rendertype=abstract.

18. Death P's. DMCH doctors assaulted, ward ransacked. Dhaka: Dly. Star; 2010.

19. Mayhem over who to use elevator. DMCH interns, DU students clash; emergency department vandalised; journos assaulted. Dhaka: Dly. Star; 2014 Available from: http://www.thedailystar.net/mayhem-over-who-to-useelevator-23038.

20. Ismail M. Rude doctors. Dhaka: Dly. Star; 2010. Available from: http://archive. thedailystar.net/newDesign/print_news.php?nid=127305.

21. Ashik M, Khan I, Ahasan HAMN, Mahbub S, Alam B. View point violence against doctors. J Med. 2010;11:167-9.

22. Rasul CH. Violence towards doctors. Bangladesh Med. J. 2012;43:1-2. [Cited 2014 April 7]. Available from: https://www.banglajol.info/index.php/BMJK article/view/13636/9809.

23. Ahasan HN, Das A. Violence against doctors. J Med. 2014;15:106-8.

24. Interns call off strike in Rangpur. Dhaka: Dly. Star; 2012. Available from: http://www.thedailystar.net/news-detail-223401.

25. Patients suffer at $\mathrm{CMCH}$. Striking interns give 24-hr ultimatum for arrest of BCL man. Dhaka: Dly. Star; 2012.

26. Treatment denied for another day. Doctors at DMCH withdraw strike an night. Dhaka: Dly. Star; 2014. Available from: http://www.thedailystar.net/ treatment-denied-for-another-day-23862

27. Coulter A, Jenkinson C. European patients' views on the responsiveness of health systems and healthcare providers. Eur J Pub Health. 2005;15:355-60. [cited 2014 Jan 14]. Available from: http://www.ncbi.nlm.nih.gov/pubmed/15975955

28. Lutwama GW, Roos JH, Dolamo BL. A descriptive study on health workforce performance after decentralisation of health services in Uganda. Hum Resour Health. 2012;10:41. [cited 2014 Jan 14]. Available from: http://www. pubmedcentral.nih.gov/articlerender.fcgi?artid=3506521\&tool= pmcentrez\&rendertype=abstract

29. Pongsupap $Y$, Van Lerberghe W. Is motivation enough? Responsiveness, patient-centredness, medicalization and cost in family practice and conventional care settings in Thailand. Hum Resour Health. 2006:4:19. [cited 2014 Jan 14]. Available from: http://www.pubmedcentral.nih.gov/ articlerender.fcgi?artid=1557862\&tool=pmcentrez\&rendertype $=$ abstract

30. Rodriguez AVD, Vituri DW, do Carmo Lourenço Haddad M, MTO V, de Oliveira WT. The development of an instrument to assess nursing care responsiveness at a university hospital. Rev da Esc Enferm da USP. 2012;46:167-74. [cited 2014 Jan 16]. Available from: http://www.ncbi.nlm.nih.gov/pubmed/22441281

31. Peabody JW, Luck J, Glassman P, Dresselhaus TR, Lee M. Comparison of vignettes, standardized patients, and chart abstraction: a prospective validation study of 3 methods for measuring quality. JAMA J Am Med Assoc. 2000;283: 1715-22. Available from: http://dx.doi.org/10.1001/jama.283.13.1715.

32. Franco LM, Daly CC, Chilongozi D, Dallabetta G. Quality of case management of sexually transmitted diseases: comparison of the methods for assessing the performance of providers. Bull World Health Organ. 1997; 75:523-32.

33. Leonard KL, Masatu MC. The use of direct clinician observation and vignettes for health services quality evaluation in developing countries. Soc Sci Med. 2005:61:1944-51.

34. Leonard KL. Masatu MC. Outpatient process quality evaluation and the Hawthorne Effect. 2006:63:2330-40.

35. Rowe AK, Lama M, Onikpo F, Deming MS. Health worker perceptions of how being observed influences their practices during consultations with ill children. Trop Dr. 2002;32:166-7.

36. Rowe SY, Olewe MA, Kleinbaum DG, McGowan JE, McFarland DA, Rochat $R$, et al. The influence of observation and setting on community health workers' practices. Int J Qual Heal Care. 2006;18:299-305.

37. Bernard HR. Research methods in anthropology: qualitative and quantitative approaches. Lanham, Maryland: Rowman Altamira; 2006. [cited 2014 Jan 23] Available from: http://books.google.com/books/about/Research_Methods in_Anthropology.html?id=LvF-afWmvlkC\&pgis=1

38. DeVellis RF. Scale development: theory and applications. Thousand Oaks: SAGE Publications; 2011. [cited 2014 Jan 22]. Available from: http://books. google.com/books?hl=en\&lr=\&id=Rye31 saVXmAC\&pgis=1.

39. Netemeyer RG, Bearden WO, Sharma S. Scaling procedures: issues and applications. Thousand Oaks: SAGE Publications; 2003. [cited 2014 Feb 12]. Available from: http://books.google.com/books?id=c2dN7HDbr7kC\&pgis=1

40. Streiner DL, Norman GR. Health Measurement Scales: A practical guide to their development and use (Google eBook). Oxford University Press; 2008 
[cited 2014 Feb 12]. Available from: http://books.google.com/books?id= UbKijeRgndwC\&pgis=1.

41. Magpi. Magpi. Washington, DC; 2014. Available from: home. http://magpi.com.

42. StataCorp. Stata statistical software: release 12. College Station: StataCorp LP; 2011. Available from: http://www.stata.com/.

43. Schonlau M. Stata Software Package, Hotdeckvar.pkg, for Hotdeck Imputation. 2006 [cited 2015 Apr 20]. Available from: http://www.schonlau.net/stata.

44. Baglin J. Improving your exploratory factor analysis for ordinal Data : a demonstration using FACTOR. Pract. Assessment, Res Eval. 2014;19:1-14.

45. Lorenzo-Seva U, Ferrando PJ. FACTOR: a computer program to fit the exploratory factor analysis model. Behav Res Methods. 2006;38:88-91.

46. Gaskin CJ, Happell B. On exploratory factor analysis: a review of recent evidence, an assessment of current practice, and recommendations for future use. Int J Nurs Stud. 2014;51:511-21. Available from: http://dx.doi.org/ 10.1016/.ijnurstu.2013.10.005

47. TenBerge JMF, Kiers HAL. A numerical approach to the approximate and the exact minimum rank of a covariance matrix. Psychometrika. 1991:56:309-15.

48. Sočan $\mathrm{G}$. The incremental value of minimum rank factor analysis. University of Groningen; 2003. http://www.rug.nl/research/portal/publications/ pub(83ad942a-3c4d-4c33-a25f-3615abcce39e).html.

49. Timmerman ME, Lorenzo-Seva U. Dimensionality assessment of ordered polytomous items with parallel analysis. Psychol Methods. 201 1;16:209-20.

50. Gadermann AM, Guhn M, Zumbo BD. Estimating ordinal reliability for Likerttype and ordinal item response data : a conceptual, empirical, and practical guide. Pract Assessment, Res Eval. 2012;17:1-12.

51. R Core Team. R. A language and environment for statistical computing. Vienna: R Foundation for Statistical Computing; 2013. Available from: http:// www.r-project.org

52. Shrout PE, Fleiss JL. Intraclass correlations: uses in assessing rater reliability. Psychol Bull. 1979;(2):86, 420-488.

53. Cicchetti DV. Guidelines, criteria, and rules of thumb for evaluating Normed and standardized assessment instruments in psychology. Psychol Assess. 1994;6:284-90.

54. Ogden J, Bavalia K, Bull M, Frankum S, Goldie C, Gosslau M, et al. "I want more time with my doctor": a quantitative study of time and the consultation. Fam Pract. 2004;21:479-83.

55. Andaleeb SS, Siddiqui N, Khandaker SA. Doctors' service orientation in public, private, and foreign hospitals. Int J Health Care Qual Assur. 2007;20:253-63.

56. Andaleeb SS. Service quality in public and private hospitals in urban Bangladesh: a comparative study. Health Policy. 2000;53:25-37.

57. Andaleeb SS. Public and private hospitals in Bangladesh: service quality and predictors of hospital choice. Health Policy Plan. 2000;15:95-102.

58. Hallgren KA. Computing inter-rater reliability for observational data: an overview and tutorial. Tutorials Quant Methods Psychol. 2012;8:23. Available from: https://www.ncbi.n/m.nih.gov/pmc/articles/PMC3402032/.

59. Zaman S. Poverty and violence, frustration and inventiveness: hospital ward life in Bangladesh. Soc Sci Med. 2004;59:2025-36. [cited 2014 Jan 9]. Available from: http://www.ncbi.nlm.nih.gov/pubmed/15351470.

60. Bloom G, Standing H, Lloyd R. Markets, information asymmetry and health care: towards new social contracts. Soc Sci Med. 2008;66:2076-87.

61. Aujoulat I, d'Hoore W, Deccache A. Patient empowerment in theory and practice: polysemy or cacophony? Patient Educ Couns. 2007;66:13-20. [cited 2015 Jan 8]. Available from: http://www.sciencedirect.com/science/article/ pii/S0738399106003247.

62. Andaleeb SS, Siddiqui N, Khandaker SA. Patient satisfaction with health services in Bangladesh. Health Policy Plan. 2007;22:263-73. [cited 2014 Jan 10]. Available from: http://www.ncbi.nlm.nih.gov/pubmed/17545252.

63. Siddiqui N, Khandaker SA. Comparison of services of public, private and foreign hospitals from the perspective of Bangladeshi patients. J Health Popul Nutr. 2007:25:221-30.

64. Andaleeb SS. Service quality perceptions and patient satisfaction: a study of hospitals in a developing country. Soc Sci Med. 2001;52:1359-70. Available from: http://www.ncbi.nlm.nih.gov/pubmed/11286361.

65. Wolf MH, Putnam SM, James SA, Stiles WB. The medical interview satisfaction scale: development of a scale to measure patient perceptions of physician behavior. J Behav Med. 1978:1:391-401.

66. Walbridge SW, Delene LM. Measuring physician attitudes of service quality J Health Care Mark. 1993;13:6-15.

67. Guyer B. Problem-solving in public health. In: Armenian HK, Shapiro S, editors. Epidemiol. Heal. Serv. Oxford: Oxford University Press; 1998. p. 15-26.

\section{Submit your next manuscript to BioMed Central and we will help you at every step:}

- We accept pre-submission inquiries

- Our selector tool helps you to find the most relevant journal

- We provide round the clock customer support

- Convenient online submission

- Thorough peer review

- Inclusion in PubMed and all major indexing services

- Maximum visibility for your research

Submit your manuscript at www.biomedcentral.com/submit 